\title{
Bioactive Glasses in Dental Applications (Literature Review)
}

\author{
Ola Saleh Mahdi \\ Department of Ceramic Engineering and Building Materials College of Materials Engineering, \\ University of Babylon, \\ engoulasaleh.alsaffar@yahoo.com
}

\begin{tabular}{|l|l|l|}
\hline Submission date:- 13/1/2019 & Acceptance date:- 15/5/2019 & Publication date:-19/5/2019 \\
\hline
\end{tabular}

\begin{abstract}
Bioactive glasses are silicate-grounded and can course of action a strong substance connect through the tissues. These biomaterials are exceptionally biocompatible and can shape a hydroxyapatite layer when embedded in the body or absorbed the recreated body liquid. Because of a few detriments, regular glass preparing technique, including softening of glass parts is supplanted by sol-gel strategy with a substantial number of advantages, for example, low handling temperature, higher immaculateness and homogeneity and along these lines better control of bioactivity. Bioactive glasses have a wide scope of utilizations, especially in dentistry. These glasses can be utilized as particulates or solid shapes and permeable or thick develops in various applications, for example, remineralization or extreme touchiness treatment. A few properties of bioactive glasses, for example, antibacterial properties can be advanced by including diverse components into the glass. Bioactive glasses can likewise be utilized to adjust diverse biocompatible materials that should be bioactive. This investigation surveys the critical advancements of bioactive glasses in dentistry. Besides, we will examine the field of bioactive glasses from starting to the present advancements, which incorporates preparing techniques, applications, and properties of these glasses.
\end{abstract}

Key words: Bioactive, Bioglasses, Dental, Hydroxyapatite, Sol-gel.

\section{1- Introduction}

Since their revelation during the 1970s by Hench, bioactive glasses have been the subject of serious examinations as biomaterials for bone tissue fix and substitution. Their appeal lies in their capacity to synthetically bond with host tissues that are specifically identified with their nuclear structure [1]. At the point when a bioactive glass is embedded, it breaks down slowly and the particles discharged advance the development of a carbonated hydroxyapatite layer at its surface. This disintegration component is improved by the low availability of the $\mathrm{SiO} 2$ organize, because of the nearness of system modifiers, similar to sodium and calcium, prompting the development of non-connecting silicon-oxygens bonds [2]. Quickly, surface $\mathrm{Na}$ and $\mathrm{Ca}$ cations are first traded with $\mathrm{H}+$ from the organic liquid, making $\mathrm{Si}-\mathrm{OH}$ bonds. On the off chance that present at first, phosphate particles can likewise be discharged. At that point, more $\mathrm{Si}-\mathrm{OH}$ bonds are framed due to the hydrolysis of $\mathrm{Si}-\mathrm{O}-\mathrm{Si}$ bonds because of a $\mathrm{pH}$ increment and they re-polymerize, making a glass surface exhausted in $\mathrm{Na}$ and $\mathrm{Ca}$ cations. The movement of $\mathrm{Ca} 2+$ and $\mathrm{PO} 4$ particles to the surface pursues, prompting the arrangement of a nebulous calcium phosphate layer, which at that point takes shape into biomimetic hydroxyapatite on account of the consolidation of hydroxide and carbonate particles from the natural liquid [3]. Since bioactivity is specifically identified with the glass disintegration rate, clearly it will likewise be subject to its morphology. The higher the explicit surface territory, i.e., the contact surface between the material and the physiological liquid, the more noteworthy the glass bioactivity. Systems to get a critical explicit surface region suggest an expansion in the porosity or potentially a decline in the measure of the materials combined. With a high surface-to-volume proportion, bioactive glass nanoparticles $(20-500 \mathrm{~nm})$ are subsequently of colossal intrigue not just on the grounds that they present a bigger explicit surface region, yet additionally a higher surface vitality contrasted with micrometric-sized particles [4]. Likewise, their nan-ometric measure permits material forming flexibility.

Journal of University of Babylon for Engineering Sciences by University of Babylon is licensed under a Creative Commons Attribution 4.0 International License. 
The bioactive nanoparticles can be scattered in a polymer framework, used to make a bioactive covering on inserts, scattered or even to be straightforwardly infused. It is significant that after diminishing their size, the scattering of nanoparticles turns out to be progressively troublesome and would thus be able to represent a test. At last, it is significant that their size additionally allows them to be disguised by various kinds of cells (macrophages, bone cells, malignant growth cells, and so on.). In the event that all around controlled and situated, this could be exceptionally intriguing for medication conveyance and malignancy treatment, for instance [5].

This survey will initially show the huge improvements of bioactive glasses in dentistry. Moreover, the examine the field of bioactive glasses from starting to the present advancements, which incorporates preparing strategies, applications, and properties of these glasses.

\section{Processing methods}

For a considerable length of time, ordinary glass innovation has been utilized to create bioactive glasses. Ablend of oxides or carbonates grains, as the glass parts, are liquefied in a platinum pot and homogenized at high temperatures up to $1250-1400^{\circ} \mathrm{C}$. At that point, to deliver a mass embed, the liquid glass is thrown into steel or graphite form. For the required resistance, a last crush and clean is frequently essential. Once in a while, bioactive glass powders are required for some clinical applications, for example, treatment of periodontal injuries. In customary glass innovation, the liquid glass is filled with water or other fluid medium to deliver little parts [6]. To accomplish powders with explicit estimate ranges for periodontal treatment, consequent crushing is fundamental. Creating bioactive glasses by regular glass innovation has a few hindrances, as very high virtue is fundamental for ideal bioactivity, which is hard to keep up in this strategy because of the high temperatures of handling, the low silica and high soluble base substance of the customary bioactive glass synthesis. Such glasses are exceptionally responsive and can break up platinum and accept other various cations as polluting influences [7]. Gross have demonstrated that M3+, M4+, and M5+ polluting influence cations in bioactive glasses effects affect tissue holding. Greenspan and Hench have uncovered how bone holding is touchy to a little measure of A13+ in bioactive glasses. Dissipation of P2O5 at high temperatures may likewise result in structure vulnerability in the ordinary technique [8]. Bioactive powders are presented to contaminants amid the customary glass preparing which applies negative impacts on bioactivity. Traditional technique forces a compositional impediment on bioactive glasses; this is a direct result of high liquids temperature of $\mathrm{SiO} 2$ and high consistency of silicate dissolves with high $\mathrm{SiO} 2$ content. The expanded generation expenses of this technique is significant which is because of high temperature preparing in platinum pots, various taking care of steps, capital hardware, work, upkeep, quality confirmation, and quality control. Low-temperature sol-gel handling offers a great option in contrast to regular glass preparing, which significantly diminishes the expenses because of bringing down the handling temperatures. This procedure has progressed toward becoming an appealing exploration field amid 1980s. Blending the metal alkoxide in the answer for combine an inorganic system, hydrolysis, gelation, and low-temperature terminating are the means for creating a sol-gel inferred glass [9]. The infinitesimal structure of such glass can be change by controlling monomer antecedent, response temperatures, water to alkoxide proportion, and impetus. In sol-gel process, numerous inconveniences of regular technique can be wiped out and the virtue, which is come about, because of preparing at low temperatures $\left(600-700^{\circ} \mathrm{C}\right)$, can be controlled. [10]. The benefits of this technique incorporate simplicity of powder creation, a more extensive territory and a superior control of bioactive, high homogeneity, great control of particles size and morphology and the simple readiness of thin movies and coatings. The sol-gel inferred bioactive glass has a permeable structure, which builds its particular surface region by two requests of extent contrasted with a dissolve-determined glass of a comparable synthesis. [10]. In this way, the rate of the outside of HAp development for the sol-gel based materials is increasingly fast. The acknowledgment that the high surface-region is great for the development of the hydroxyapatite layer holding prompted utilization of the sol-gel procedure to make bioactive glasses [11]. A ternary bioactive glass with a beginning surface zone more prominent than $150 \mathrm{~m} 2 / \mathrm{g}$, for bone join applications, that exhibited that bioactive glasses with surface regions more noteworthy than $50 \mathrm{~m} 2 / \mathrm{g}$ could cling deep down and delicate tissue inside $24 \mathrm{~h}$ of in vitro explore[12].

\section{The mechanism of hydroxyapatite layer formation on bioactive glasses}

Hydroxyapatite is like the bone mineral and can connect with collagen fibrils of harmed issue that remains to be worked out with it. Protein adsorption, fuse of collagen fibrils, connection of bone forebear 
cells, cell separation, the discharge of bone extracellular grid and its mineralization are engaged with the arrangement of HAp layer-bone bond. Osteogenesis, because of the disintegration results of the glass on osteoprogenitor cells, invigorates new bone development [13].The system of HAp layer development on bioactive glasses has been broadly considered in vitro and in vivo. This procedure includes diverse stages; calcium particles break up from the bioactive glass into the body liquid while a silica-rich interlayer frames on the glass surfaces. The nucleation of HAp is presently conceivable because the encompassing liquid is supersaturated regarding HAp because of the disintegration of the calcium particles. What's more, silica-rich interlayer breaks down a lot of silicate particle and gives ideal locales to the nucleation. The procedure of nucleation and development of the HAp layer proceeds by the responses of the calcium, phosphate, and hydroxide particles. It is conceivable that carbonate or fluoride anions consolidate in the responses, too [13].SBF is an answer that reenacts human blood plasma with particle syntheses like human blood, yet with no proteins, hormones, glucose, or nutrients . Amid submersion in SBF, distinctive procedures happen all the while which result in auxiliary and substance changes to the outside of the material .These procedures are filtering, corruption,, and precipitation [14].In the filtering procedure, through the trading of the cations $\mathrm{H}+$ and $\mathrm{H} 3 \mathrm{O}$,, metal particles like $\mathrm{Na}+$ and $\mathrm{Ca} 2+$ are discharged and the $\mathrm{pH}$ at the interface increments up to 7.4. In parallel, hydroxyl particles locally break the silica-oxygen holding. At that point, silicon as silicic corrosive, $\mathrm{Si}(\mathrm{OH}) 4$, is discharged into the arrangement. [15]. The hydrated silicic corrosive superficially is encompassed by no less than one hydroxyl gathering; along these lines, a silicic corrosive gel layer shapes. At the same time, the glass discharges calcium and phosphorus and an undefined calcium phosphate-rich stage is shaped superficially. The CaP stage at that point takes shape into a hydroxyapatite (HAp) structure [16].

\section{Mechanical properties}

The utilization of bioactive glasses, because of their low mechanical quality and inborn weakness, has been constrained to non-stack bearing parts, for example, ossicles in the center ear. Joining of nitrogen into the silicate system can address the issue of low quality in glasses. At the point when oxygen is supplanted by nitrogen in alumino-silicate glasses, flexible modulus and hardness increment straightly with nitrogen content; be that as it may, glass change temperature increments, also. Joining of nitrogen likewise results in more prominent moderate break development opposition, unassuming additions in crack obstruction, and expanded viscosities [17].Expansion of both fluorine and nitrogen can expand the mechanical properties as fluorine instigates extensive decreases in both glass liquefying temperatures (Tm) and glass change temperatures ( $\mathrm{Tg}$ ) while flexible modulus and hardness increment with nitrogen fuse yet they are unaffected by fluorine fuse. The disintegration of nitrogen into the glass soften is additionally encouraged by fluorine [18].

\section{Dentistry Application of Bioactive Glasses}

In 1986, a bioactive glass was effectively utilized as center ear prosthesis to fix conductive hearing misfortune and it was the primary clinical utilization of such material. In tooth extraction, bioactive glasses have been utilized to save the stature of the alveolar edge [19].Bioactive glasses likewise have been utilized for spinal combination, remaking of the iliac peak following autograft gathering, and for filling hard imperfections in various orthopedic methodology. Dental earthenware production ought to have explicit properties, for example, high quality, crack sturdiness, wear opposition, closeness with regular tooth structure and long life in the oral condition, to be utilized in therapeutic dentistry. [20]. To effectively put the settled rebuilding efforts in the oral condition, it is important to keep periodontal tissues solid. Settled rebuilding efforts increment the neighborhood plaque gathering, particularly with poor oral cleanliness, and lead to irritation, loss of connection and in the long run periodontal tissue's breakdown. Presence of a negligible hole between the tooth and rebuilding which is presented to oral microbes results in mash disturbance or corruption, auxiliary caries and bond disintegration, all being the normal reasons of settled prosthetic reclamation disappointment [21]. It is unimaginable for artistic materials to grow new connection on their surface. Thusly, regardless of the capacity of settled artistic reclamations to regenerate the morphology and capacity of the harmed structure, they cannot totally append to the periodontal tissue. Actually, customary dental pottery are biocompatible however not bioactive. Thusly, if these potteries would be adjusted such that they could invigorate bioactive conduct around the settled rebuilding efforts edges and give a bioactive surface, through the tissue regenerative systems, they could create periodontal tissue connection and make finish fixing of the minor hole. [22]. 
This fixing could keep the disappointment of settled artistic reclamations by wiping out auxiliary caries, micro penetration of the oral microscopic organisms and their bond on concrete surface. It is normal that usage of guided tissue recovery strategies in the field of dental pottery can give answers for location settled prosthetic reclamations disappointment [23]. This procedure can result in arrangement of new connections on the tooth surfaces (for example cementum) or on embed surfaces (Titanium, hydroxyapatite, and so on.). Thusly, if dental earthenware production could show a concrete like conduct, the natural surface required for connection of the cells would be given and tissue connection would be advanced. [24]. Development of apatite on the dental artistic surface can improve the tissue connection since cementum comprises of natural hydroxyapatite. As referenced previously, bioactive glasses can reestablish rigid imperfections and build up another connection on tooth surfaces. The solid and stable holding results from improvement of a hydroxyapatite layer, like that of the bone, superficially after consideration into natural condition [25]. Here and there, natural apatites incorporate hints of inorganic components that can be substituted in the apatite grid or adsorbed on the apatite surface. Bioactive materials can shape this organic apatite on their surface in vitro under different drenching conditions Improvement of apatite on the dental artistic surfaces through alteration with bioactive glasses has been attempted by a few specialists. In 2003, a bioactive glass covered a dental artistic and after submersion in SBF; the development of a very muchconnected apatite layer superficially was watch. In addition, it was accounted for that the connection and multiplication of human periodontal tendon cells can be upheld by dental ceramic- bioactive glass blends.

Of course, sol-gel strategy can make a progressively permeable surface, which raises the disintegration rate, and advances apatite arrangement, so dental earthenware bioactive glass blend arranged by such technique can quicken the beginning of HAp development. In 2010, two sol-gel determined materials were effectively created for dental applications: a novel earthenware and a bioactive blend (artistic 30 wt.\%bioactive glass $58 \mathrm{~S} 70 \mathrm{wt} . \%$ ) with better control of structure, microstructure and properties because of high homogeneity given by the sol-gel strategy, contrasted with soften inferred pottery [26]. In softening powder arrangement methods, the surface reactivity of earthenware production has been debilitated by high response temperature, which results in high heterogeneity and loss of porosity and their surface territory depends just on the molecule size of the powders[27] . Then again, the sol-gel strategy gives command over the textural properties (explicit surface region and porosity) and precious stone structure that builds up an enhanced bioactive surface and furthermore keeps up the surface bioactivity over a more extensive piece of silica content [28].

\section{Conclusions}

Bioactive glasses can cling to both delicate and hard tissue and advance the bone development. The bioactivity conduct of these glasses is identified with the development of an organically dynamic hydroxyapatite layer on the outside of the glasses. The component of holding of bioactive glasses to tissues incorporates a progression of surface responses that happen when the glass is presented to a fluid situation. These glasses are created through two fundamental strategies, softening and sol-gel handling. The last has numerous focal points, which make it a great strategy to furnish glasses with fine permeable surfaces and upgraded bioactivity. Bioactive glasses have a wide scope of utilizations, for example, bone unions, platforms, covering materials, and are utilized for extreme touchiness treatment. A standout amongst the most imperative properties of bioactive glasses is their capacity to display antibacterial action, which makes a microscopic organism's free condition while recuperating and recovering the deformity region. The advancement of this capacity is conceivable by doping antibacterial components, for example, silver, copper or zinc to such glasses. Another property of bioactive glasses is mechanical property, which can be enhanced by acquainting nitrogen and fluorine with the silicate system of the glasses. Alternate properties of bioactive glasses can likewise be adjusted by fuse of various particles, for example, strontium and phosphates. These possibilities of bioactive glass make it a one of a kind material to be broadly utilized in dentistry. For instance, alteration of dental earthenware production with sol-gel infers bioactive glasses is a standout amongst the most alluring uses of these glasses in dentistry. Such materials can invigorate bioactive conduct around the settled rebuilding efforts edges and give a bioactive surface. Along these lines, they can create periodontal tissue connection and make finish fixing of the minimal hole. This fixing can keep the disappointment of settled earthenware rebuilding efforts by dispensing with the auxiliary caries, micro penetration of oral microscopic organisms and their bond on the concrete surface. 


\section{CONFLICT OF INTERESTS.}

- There are no conflicts of interest.

\section{References}

[1] F.Bahmad, J. Merchant, "Histopathology of oscula grafts and implants in chronic otitis media", Ann. Otol. Rhinol. Laryngol, vol. 116, pp181-191, 2007.

[2] N. Abo Elsaad, Soory M, Gadalla LMA, "Effect of soft laser and bioactive glass on bone regeneration in the treatment of infra-bony defects (a clinical study)", Lasers Med Sci vol.24, pp 387-395, 2009.

[3] P.N.Gunawidjaja, A.Y.H. Lo, I. Izquierdo-Barba, A García, D Arcos, B. Stevensson, J.Grins," Biomimetic apatite mineralization mechanisms of mesoporous bioactive glasses as probed by multinuclear 31P, 29Si, 23Na and 13C solid-state NMR.” Journal of Phys. Chem, vol. 114, pp19345$19356,2010$.

[4] L.L. Hench,” Bioceramics: From concept to clinic.” Journal of American Ceram. Soc., vol.74, 1487$1510,2011$.

[5] D.G. Gillam, H.S Seo, J.S Bulman, “. Perceptions of dentine hypersensitivity in a general practice population.” Journal Oral Rehabil, vol. 26, pp710-714, 2011.

[6] M. Downing, U. Johansson, L. Carlsson, J.Walliker, P.Spraggs, H.Dodson, I. Albrektsson, "boneanchored percutaneous connector system for neural prosthetic applications", Journal of Ear Nose Throat, vol. 76, pp328-332, 2012.

[7] Q. Fu, E.Saiz, M.Rahaman, A.P. Tomsia," Toward strong and tough glass and ceramic scaffolds for bone repair", Advanced Functional Materials, vol.23, pp 5461-5476, 2013.

[8] P.González, J. Serra, S.Liste, S.Chiussi, B. León,” Raman spectroscopic study of bioactive silica based glasses." Journal of Non-Cryst. Solids vol. 320, pp 92-99, 2014.

[9] D.C. Greenspan, J.P. Zhong, G.P.Latorre," Effect of surface area to volume ratio on in vitro surface reactions of bioactive glass particulates.”, Bioceramics ,vol.7,pp 28-35, 2015.

[10] L.L Hench, D.Greenspan, "Interactions between bioactive glass and collagen: A review and new perspectives.” Journal of Aust. Ceram. Soc., vol. 49, pp 1-40. 2012.

[11] J.R. Jones," Review of bioactive glass: From Hench to hybrids.” Acta Biomater vol. 9, pp4457-4486, 2013.

[12] J.R Jones, D.S.Brauer, L Hupa, D.C. Greenspan,” Bioglass and bioactive glasses and their impact on healthcare.” Journal Int. Appl. Glass Sci, vol. 7, pp 423-434. 2016.

[13] I. M. O.Kangasniemi, M. Kawabata, M.P Hector, G.R. Davis," Diffusive transport within dentinal tubules: an X-ray micro tomographic study." Arch Oral Biol., vol.53, pp736- 743, 2008.

[14] E .Kontonasaki, N .Kantiranis, L. Papadopoulou," Microstructural characterization and comparative evaluation of physical, mechanical and biological properties of three ceramics for metal ceramic restorations". Dent Mater, vol.24, pp 1362-1373, 2009.

[15] E. Kontonasaki, L. Papadopoulou, T. Zorba, "Apatite formation on dental ceramics modified by bioactive glass" Journak of Oral Rehabil, vol. 30,pp 893-902, 2003.

[16] G. Laudisio, F.Branda," Sol-gel synthesis and crystallization of $3 \mathrm{CaO} .2 \mathrm{SiO}_{2}$ glassy powders." Thermochim Acta, vol., 370, pp 119-124, 2001.

[17] S. Liu, W.Gong, Y.Dong, Q.Hu, X .Chen," The effect of submicron bioactive glass particles on in vitro osteogenesis." RSC Adv, vol. 5, pp 38830-38836. 2015. 
[18]A. Marc Andre, Meyers, Po-Yu Chen, Albert Yu-Min Lin, Yasuaki eki,"Biological Materials: Structure and mechanical properties", Progress in Materials Science, vol 53, pp. 1-206, 2009.

[19] G.E. Merwin, "Bioglass middle ear prosthesis: Preliminary report." Ann. Otol. Rhinol. Laryngol. vol.95, pp 78-82. 2000.

[20] S.K. Misra, D.Mohn, T.J. Brunner, W.J.Stark, S.E.Philip, I.Roy, V.Salih, J.C. Knowles, A.R. Boccaccini," Comparison of nanoscale and microscale bioactive glass on the properties of P(3HB)/Bioglass" Journal of Biomaterials, vol. 29,pp 1750-1761. 2004.

[21] R.Reck, S Störkel, A.Meyer," Bioactive glass-ceramics in middle ear surgery an 8-year review." Ann. N. Y. Acad. Sci., vol. 523, pp 100-106, 2008.

[22] A.J. Salinas, M.Vallet-Regi,” The sol-gel production of Bioceramics.” Key Eng. Materials vol.391, pp 141-158, 2010.

[23] B.J. Tai, Z .Bian, H. Jiang, “ Anti-gingivitis effect of a dentifrice containing bioactive glass (NovaMin) particuAbbasi “, Journal of Dent Biomater, vol.9 ,pp;33:86-91,2015.

[24] S.Teixeira, , M. Magallanes., A.de Aza Mateus, A.Y.Rodriguez, M.A. Peña ,P.,Ferraz, M.P. de Aza, S.,Monteiro, ,"Cell culture studies on hydroxyapatite and wollastonite-tricalcium phosphate based materials for tissue engineering", European Cells and Materials vol. 14, ,pp.95-105 ,2009.

[25] T .Turunen, J .Peltola, A. Yli-Urpo," Bioactive glass granules as a bone adjunctive material in maxillary sinus floor augmentation." Clin Oral Implants Res., vol.15, pp135- 141, 2011.

[26] T. Waltimo, D. Mohn, F. Paque, "Fine-tuning of bioactive glass for root canal disinfection. Journal of Dent Res, vol.88, pp235-238. 2013.

[27] J.Wilson, D.E.Douek, K.Rust," Bioglass middle ear devices: Ten year clinical results.” Journal of Bioceramics, vol. 8, pp 239-245, 2006.

[28] V.S. Yadav, S.C. Narula, R.K. Sharma," Clinical evaluation of guided tissue regeneration combined with autogenous bone or autogenous bone mixed with bioactive glass in intrabony defects." Journal of Oral Sci., vol.53:481-488, 2011. 


\section{تطبيقات الزجاج الحيوي في طب الأسنان (ملخص مراجع) \\ عُلا صالح مهذي}

قسم هندسة السبيرميك ومواد البناء، كلية هندسة المواد، جامعة بابل

engoulasaleh.alsaffar@yahoo.com

الخلاصة

يكون الزجاج الحيوي من اساس سيليكات يمكنها ترتيب ارتباط كيميائي القوي مع الأنسجة. هذه المواد الحيوية منو افقة حيويا

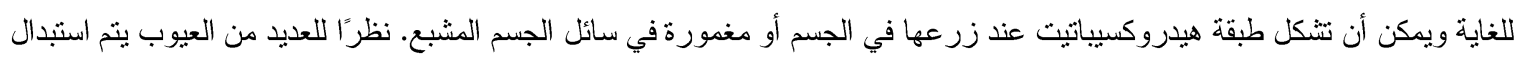

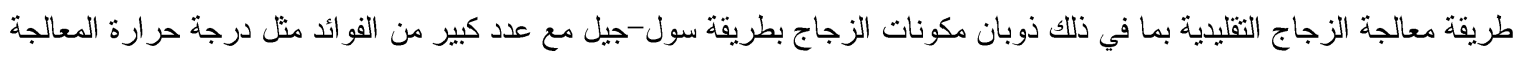

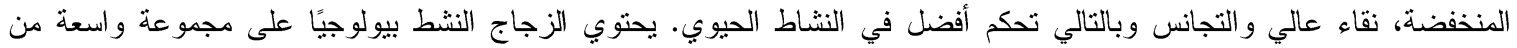

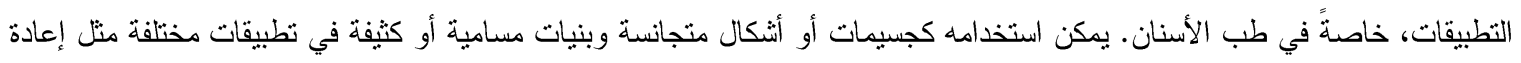

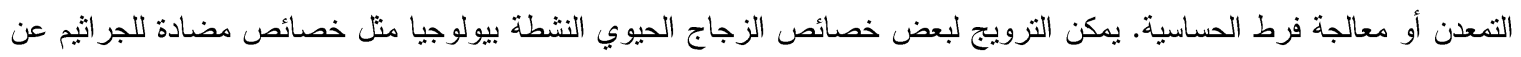

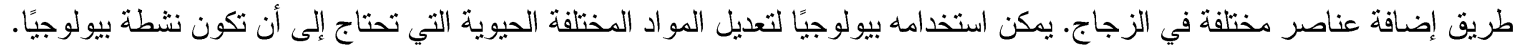

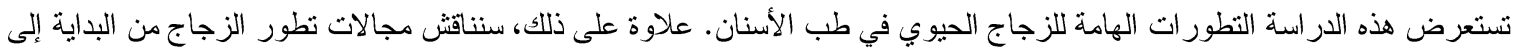

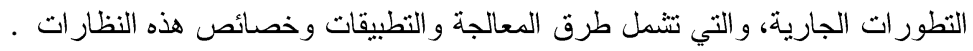
الكلمات الدالة :التو افقية الحياتية، الزجاج الحياتي، الاسنان، الهيدروكسي ابتايت، سول-جل. 